\title{
Inhaled drug delivery: A practical guide to prescribing inhaler devices
}

\author{
Pierre Ernst MD \\ Respiratory Division, Montreal General Hospital; McGill University, Montreal, Quebec
}

\begin{abstract}
P Ernst. Inhaled drug delivery: A practical guide to prescribing inhaler devices. Can Respir J 1998;5(3):180-183.
\end{abstract}

Direct delivery of medication to the target organ results in a high ratio of local to systemic bioavailability and has made aerosol delivery of respiratory medication the route of choice for the treatment of obstructive lung diseases. The most commonly prescribed device is the pressurized metered dose inhaler (pMDI); its major drawback is the requirement that inspiration and actuation of the device be well coordinated. Other requirements for effective drug delivery include an optimal inspiratory flow, a full inspiration from functional residual capacity and a breath hold of at least $6 \mathrm{~s}$. Available pMDIs are to be gradually phased out due to their use of atmospheric ozonedepleting chlorofluorocarbons (CFCs) as propellants. Newer pMDI devices using non-CFC propellants are available; preliminary experience suggests these devices greatly increase systemic bioavailability of inhaled corticosteroids. The newer multidose dry powder inhalation devices (DPIs) are breath actuated, thus facilitating coordination with inspiration, and contain fewer ingredients. Furthermore, drug delivery is adequate even at low inspired flows, making their use appropriate in almost all situations. Equivalence of dosing among different devices for inhaled corticosteroids will remain imprecise, requiring the physician to adjust the dose of medication to the lowest dose that provides adequate control of asthma. Asthma education will be needed to instruct patients on the effective use of the numerous inhalation devices available.

Key Words: Aerosols, Asthma, COPD, Drug therapy

\section{Administration des médicaments en inhala- tion : un guide pratique pour prescrire des ap- pareils d'inhalation}

RÉSUMÉ : L'administration directe d'une médication dans un organe cible résulte en un ratio élevé entre la biodisponibilité locale et générale, faisant ainsi de l'administration par aérosol de la médication respiratoire la voie privilégiée pour le traitement des maladies pulmonaires obstructives. L'appareil le plus souvent prescrit est l'aérosol-doseur; son désavantage majeur est qu'il nécessite une bonne synchronisation entre l'inspiration et le déclenchement du système. Les autres conditions pour l'administration adéquate du médicament comprennent un débit inspiratoire optimal, une inspiration complète à partir de la capacité résiduelle fonctionnelle et une période d'apnée d'au moins 6 secondes. Les aérosols-doseurs disponibles disparaîtront progressivement du marché parce qu'ils utilisent des chlorofluorocarbones (CFC), nuisibles à la couche d'ozone, comme propulseurs. Un nouveau type d'aérosols-doseurs ne faisant pas appel à ce moyen de propulsion est maintenant disponible ; les premières études laissent croire que ces appareils augmentent énormément la biodisponibilité générale des corticostéroïdes en inhalation. Les nouveaux inhalateurs de poudre sèche à multidoses sont actionnés par l'inspiration, favorisant ainsi une bonne coordination avec l'inspiration ; en outre, ils contiennent moins d'ingrédients. De plus, la diffusion du médicament est adéquate même lorsque le débit inspiratoire est peu élevé ce qui permet d'utiliser ces inhalateurs dans presque toutes les situations. L'équivalence du dosage parmi les différents appareils d'inhalation de corticostéroïdes demeurera imprécise, exigeant du médecin qu'il ajuste la dose de médication à la dose la plus faible qui permet une bonne maitrise de l'asthme. Dans un contexte d'éducation sur l'asthme, il faudra montrer aux patients asthmatiques comment utiliser efficacement les nombreux inhalateurs disponibles sur le marché.
$\mathrm{I}^{\mathrm{n}}$ $n$ this paper I hope to provide readers with an understanding of the factors that significantly affect the quantity of medication delivered by the various inhalation devices available. I also suggest an approach to changing patients from the current pressurized metered dose inhalers (pMDIs), containing chlorofluorohydrocarbons (CFC) that will not be avail- able indefinitely, to the newer inhalation devices now being introduced.

During the past 20 years the inhaled route for delivery of medications for the treatment of asthma has gradually supplanted the oral route as the preferred method of drug delivery for most patients. This was in large part due to the effi-

Correspondence and reprints: Dr Pierre Ernst, Respiratory Epidemiology Unit, 1110 Pine Avenue West, Montreal, Quebec H3A 1A3. Telephone 514-398-6974, fax 514-398-8981, e-mail ernst@ meakins.lan.mcgill.ca 
cacy and ease of use of the widely prescribed pMDIs containing CFCs as a propellant. Such rapid and direct delivery of medication to the target tissue greatly reduces the dose of medication and the frequency and severity of adverse effects. As a consequence of an international treaty to protect the atmospheric ozone layer (Montreal Protocol on Substances That Deplete the Ozone Layer), CFCs are gradually being replaced as the preferred propellant for the delivery of medication to the airways of patients with obstructive airways disease. Patients currently using CFC-based pMDIs will have to change either to a pMDI that uses the newer, more environmentally friendly, propellant gases or to a multidose dry powder inhaler device (DPIs). This switch will require education of patients and determination of the therapeutic equivalence of drugs when substituting one device for another, or one type of medication for another within each class of drug.

While there is little doubt as to the efficacy of drug delivery with both the CFC and non-CFC propelled pMDIs and the newer multidose dry powder inhalation devices when they are used properly, inadequate technique, with suboptimal drug delivery, is very common. Inadequate technique has been reported among anywhere from $12 \%$ to $89 \%$ of subjects (1). Among patients who do acquire this skill, up to one-fifth regress to previous bad habits or develop new ones (2). The only way to discern improper inhalation technique is by asking patients to demonstrate their inhaler use at every opportunity.

Once the basic technique has been mastered, the principal determinants of how much medication is delivered to the airways are particle size, the rate of inspiration, the volume of air inspired and the duration of breath hold at the end of inspiration $(1,3)$. The particle size is set by the design of the device, though it may be modified somewhat by changes in temperature and humidity, significantly so at extremes of temperature and humidity. The rate of inspiration can drastically change the amount of medication delivered to the airways, and this can pose a problem, especially for some DPIs of older design (eg Rotahaler, Diskhaler, Glaxo Wellcome plc, London, United Kingdom) which require very high inspiratory flows (100 L/s or more) for adequate drug delivery (4). The requirement for such an inspiratory effort limits the usefulness of such devices in the very young or old, or in patients with severe airflow limitation. The volume of inspiration is important, and drug delivery may be improved if the breath is initiated at functional residual capacity, that is, at the end of a relaxed expiration as opposed to asking the patient to breathe out completely to residual volume that may cause smaller airways to collapse (5). A breath hold at end inspiration of at least $5 \mathrm{~s}$ is needed, with drug delivery continuing to improve significantly for up to $10 \mathrm{~s}(5,6)$. Whether a pMDI is placed in the open mouth or held at two finger breadths in front of the mouth is of only minor importance, though it is the author's experience that the latter technique reduces the likelihood of significant deposition on the tongue or hard palate in many patients.

While available CFC pMDIs are both practical and port- able, allowing accurate and consistent dosing in most cases, certain characteristics of the devices require attention to assure adequate drug delivery. If an inhaler is not used for a week or more, the dose of medication may have escaped from the metering chamber and a full dose may not be obtained on initial actuation (7). This phenomenon is of increasing importance in light of current recommendations to use short-acting beta-agonists on an as-needed basis (8). Patients should be instructed to prime the device by actuating it once or twice before such intermittent use. Storage position of pMDIs, even when storage is not prolonged, may alter the quantity of drug in the first actuation (7). This may not be noticeable to the patient, however, because the amount of propellant, the greater part of the plume, remains the same. Finally, as with all inhalation devices, the proportion of medication deposited in the lungs varies with the rate of inspiration; breathing in too quickly after activation of pMDIs substantially reduces the dose delivered to the lungs (6).

Multidose devices, both pMDIs and DPIs, show a tail-off phenomenon in the dose delivered when nearly empty; it therefore appears advisable in patients in whom the dose is critical to advise against the use of these devices past the number of recommended doses, even when the pMDI appears to be producing an adequate plume (9). For the Turbuhaler (Astra Pharma Inc), a dry powder device, patients need to be instructed to start a new inhaler upon appearance of the red tag in the dosing window; patients may be misled by shaking the inhaler and feeling the movement of the desiccant.

The principal difficulty experienced by patients using pMDIs is in coordinating the timing of inspiration with actuation of the device. This problem can be overcome by connecting the pMDI to a spacer (10). These add-on devices allow the aerosolized medication, especially the smaller particles most likely to be delivered successfully to the lower airway, to remain suspended for one or two seconds, thus providing the patient with sufficient time to initiate a deep inspiration (11). For patients unable to hold their breath for at least $5 \mathrm{~s}$, a one-way valve at the proximal end of the spacer allows the patient to obtain an adequate dose by three or four tidal breaths in adults and five or six normal breaths in young children (12). For patients who are unable to produce a tight seal around the mouthpiece of the spacer, that is most children under the age six years, as well as some subjects with facial paralysis, there are spacer devices with face masks of different sizes (13).

To be effective, spacers should have a volume of at least $110 \mathrm{~mL}$ and, as a result, are bulky (14); many patients are therefore unwilling to carry these devices around. Patients must be reminded to shake the pMDI before use, something they tend to forget when the pMDI is left attached to the spacer device. Furthermore, patients should be warned against discharging more than one dose at a time of the pMDI into the spacer because this drastically reduces the total dose delivered per actuation (15). Certain spacers may have a strong electrostatic charge, especially if new (16). Washing a new spacer in mild dish soap may be necessary if previously effective doses are insufficient. The variety and quality of 
currently available volume spacers make the use of wet nebulization unnecessary in almost all patients, whatever their age or the severity of their condition. There have been several reports demonstrating conclusively that bronchodilator therapy in acute severe asthma can be delivered as effectively as, and more efficiently and at lower cost using pMDIs attached to a spacer device than with wet nebulization (17).

Another way to circumvent problems in coordinating actuation of the inhaler with early inspiration is to use a breath actuated device, most commonly a DPI, though more recently breath actuated pMDIs have become available. These newer breath actuated pMDIs deliver the plume of propellant and medication once the patient has overcome a resistance equivalent to an inspiratory flow of $30 \mathrm{~L} / \mathrm{min}$; there is at least a theoretical concern that this resistance might not be overcome during a severe asthma attack. As mentioned previously, many older DPIs require quite high inspiratory flows for optimal performance. Furthermore, the active ingredient is often mixed with a large amount of vehicle, usually lactose, that may induce cough and that many patients find unpleasant to inhale.

In contrast, the Turbuhaler, a multidose (ie, requires no loading) breath actuated DPI, delivers only the active ingredient in powder form. Patients are usually unaware of inhaling anything but air. For this reason they need to be warned lest they think no medication is being delivered. This is of critical importance with budesonide, the inhaled steroid delivered via the Turbuhaler, because patients do not receive immediate feedback as to the efficacy of the therapy. In our practice, the Turbuhaler has become the most popular inhaler device both from the patient's point of view, with approximately half of new referrals started on or switched to this device, and by our educators who find the technique of use simple to teach. The device is both practical and portable, and does not require use of a spacer device. A further advantage is the formulation of terbutaline and budesonide as pure medication delivered by the Turbuhaler with no additives to be inhaled. This avoids the potential for adverse reactions seen occasionally in patients due the emulsifiers and preservatives contained in most pMDIs. The Diskus, a new multi-dose DPI, recently launched by Glaxo Wellcome will have many of the advantages of the Turbuhaler but with the addition of a dose counter.

The frequency of oral candidiasis secondary to the use of inhaled corticosteroids delivered by Turbuhaler is low and similar to that seen with current pMDIs attached to a large volume spacer (18). Oral candidiasis can be prevented almost completely by thorough mouth rinsing and gargling after use and by bid dosing as opposed to qid. Delivery of the inhaled corticosteroid budesonide to the airway with the Turbuhaler is twice that obtained using a conventional pMDI and equivalent to the amount deposited in the lower airway using the pMDI with a large volume spacer $(18,19)$. Increasing inspiratory flow from $30 \mathrm{~L} / \mathrm{s}$ (the usual inspiratory flow recommended for pMDIs) to $60 \mathrm{~L} / \mathrm{s}$ doubles lung deposition and may permit a substantial reduction in the dose of inhaled corticosteroid required to maintain symptom control (20).
This may in turn result in substantial cost savings. (A flow of approximately $60 \mathrm{~L} / \mathrm{min}$ can be obtained by asking patients to breathe in rapidly).

The bronchodilator effect of the beta-agonist terbutaline delivered by Turbuhaler is adequate at inspiratory flows as low as $15 \mathrm{~L} / \mathrm{s}$ and has been used effectively in the treatment of acute severe asthma in the emergency room (21). The therapeutic effect obtained is equivalent to that seen with wet nebulization or with a pMDI attached to a large volume spacer.

Nonchlorinated propellants to replace CFCs have been developed and consist of hydrofluoroalkanes (HFAs) (22). These are less reactive and persist in the atmosphere for a much shorter time than CFCs. 3M is the only company, to date, to bring to market a pMDI using an HFA type propellant. This is only recently available in Canada, and our experience with this product is therefore quite limited. Information published or presented at scientific meetings thus far suggest that this device provides much improved drug delivery to the lungs in the case of the inhaled corticosteroid beclomethasone, with $50 \%$ or more reaching the airway compared with approximately $25 \%$ to $30 \%$ in the case of the traditional pMDI attached to a large volume spacer. Delivery of the beta-agonist albuterol is approximately equivalent without a spacer but increased when such a device is attached $(23,24)$. A smaller delivered volume may again worry patients about whether they are receiving an adequate dose. In addition to improved delivery of inhaled corticosteroids, the $3 \mathrm{M}$ inhaler provides less acute bronchospasm ("cold freon effect'), and there is less variation of dose with storage and exposure to cold temperatures (7).

The impending disappearance of conventional CFC propelled pMDIs will require physicians to switch a large number of patients to other delivery devices. At this time it appears wise to choose one of the newer devices for patients whose therapy is being initiated and patients who require changes in their current asthma therapy. This will allow busy asthma practices to spread out the very substantial educational effort that will be required over the next several years. Not only will patients need to acquire new skills, they will also have to be reassured about the safety and efficacy of the newer formulations (24).

Choosing an equivalent dose when switching patients who are well controlled on a given dose of inhaled corticosteroid to a non-CFC pMDI or to one of the newer multidose DPIs will be beset with uncertainty. Equivalent doses are likely to vary from patient to patient and in the same patient if, as commonly occurs, inhalation technique changes over time. A simple rule of thumb might be to decrease the dose of inhaled corticosteroid by half for the same medication (usually beclomethasone) when switching from a traditional pMDI to the new 3M non-CFC pMDI. Similarly the dose should be cut in half when changing to budesonide via Turbuhaler. If the patient has been using a large volume spacer on a regular basis, a similar dose should be prescribed (18). This process is made all the more difficult by the availability of a large number of inhaled corticosteroids for which equivalent doses are uncertain and likely to be significantly affected 
by the delivery device chosen. Close follow-up of patients will be required with readjustment of doses at intervals of two to four weeks in order to identify the lowest dose of inhaled corticosteroids that provides optimal control of symptoms and lung function. Given the rapid onset of bronchodilation with the short-acting beta-agonists and their prescription on an as-needed basis, choosing an equivalent and effective dose will likely be much less difficult (25).

The therapeutic armamentarium for the treatment of asthma is increasing in both effectiveness and complexity. Deriving the most benefit from available drug therapy will require close collaboration between patients and their physicians, and this collaboration is likely to be most effective with the availability of a structured educational intervention.

\section{REFERENCES}

1. McFadden ER Jr. Improper patient techniques with metered dose inhalers; clinical consequences and solutions to misuse. J Allergy Clin Immunol 1995;96:278-83.

2. De Blaquière $\mathrm{P}$, Christensen DB, Carter WB, Martin TR. Use and misuse of metered-dose inhalers by patients with chronic lung disease. Am Rev Respir Dis 1989;140:910-6.

3. Tobin MJ. Use of bronchodilator aerosols. Arch Intern Med 1985;145:1659-63.

4. Clark AR. Medical aerosol inhalers: past, present and future. Aerosol Sci Technol 1995;22:374-91.

5. Newman SP, Clarke SW. The proper use of metered dose inhalers. Chest 1984;86:342-4.

6. Newman SP, Pavia D, Clarke SW. How should a pressurised beta-adrenergic bronchodilator be inhaled? Eur J Respir Dis 1981;62:3-20.

7. Schultz RK. Drug delivery characteristics of metered-dose inhalers. J Allergy Clin Immunol 1995;96:284-7.

8. Ernst P, Fitzgerald M, Spier S. Canadian Asthma Consensus Conference. Summary of Recommendations. Can Respir J 1996;3:89-100.

9. Baldwin JL, Meltzer EO. Should MDI's be used until they are completely empty? J Respir Dis 1993:14;1222-3.

10. Konig P. Spacer devices used with metered-dose inhalers: breakthrough or gimmick? Chest 1985;88:276-84.
11. Ahrens R, Lux C, Bahl T, Han S-H. Choosing the metered-dose inhaler spacer or holding chamber that matches the patient's needs: Evidence that the specific drug being delivered is an important consideration. J Allergy Clin Immunol 1995;96:288-94.

12. Gervais A, Bégin P. Bronchodilatation with a metered dose inhaler plus an extension using tidal breathing vs jet nebulization. Chest 1987;92:822-4.

13. Agertoft L, Pedersen S. Influence of spacer device on drug delivery to young children with asthma. Arch Dis Child 1994;71:217-20.

14. Chua HL, Chambers CB, Newhouse MT. Comparison of MDI's and MDI's with four add-on devices on lung aerosol deposition and function in asthmatics. J Aerosol Med 1995;8:89. (Abst)

15. Clark DJ, Lipworth BJ. Effect of multiple actuations, delayed inhalation and antistatic treatment on the lung bioavailability of salbutamol via a spacer device. Thorax 1996;51:981-4.

16. Wildhaber JH, Devadason SG, Eber E, et al. Effect of electrostatic charge, flow, delay and multiple actuations on the in vitro delivery of salbutamol from different small volume spacers for infants. Thorax 1996;51:985-8.

17. Newhouse MT. Emergency department management of life-threatening asthma: are nebulizers obsolete? Chest 1993;103:661-3.

18. Toogood JH, White FA, Baskerville JC, Fraher LJ, Jennings B. Comparisons of the antiasthmatic, oropharyngeal and systemic glucocorticoid effects of budesonide administered through a pressurized aerosol plus spacer or the Turbuhaler dry powder inhaler. J Allergy Clin Immunol 1997;99:186-93.

19. Thorsson L, Edsbäcker S, Conradson T-B. Lung deposition of budesonide from Turbuhaler is twice that from a pressurized metered-dose inhaler. Eur Respir J 1994;7:1839-44.

20. Persson G, Olsson B, Soliman S. The impact of inspiratory effort on inspiratory flow through Turbuhalar in asthmatic patients. Eur Respir J 1997;10:681-4.

21. Tonnesen F, Laursen LC, Evald I, Stahl E, Ibsen TB. Bronchodilating effect of terbutaline powder in acute severe bronchial obstruction. Chest 1994;105:697-700.

22. Jenkins M. Clinical evaluation of CFC-free metered dose inhalers. J Aerosol Med 1995;8(Supp 1):S41-7.

23. Huchon G. Metered dose inhalers past and present: advantages and limitations. Eur Respir Rev 1997;7:29-31.

24. Bleecker E. Clinical reality: the safety and efficacy of the world's first CFC-free MDI. Eur Respir Rev 1997;7:37-9.

25. Barry PW, O'Callaghan C. In vitro comparison of the amount of salbutamol available for inhalation from different formulations used with different spacer devices. Eur Respir J 1997;10:1345-8. 


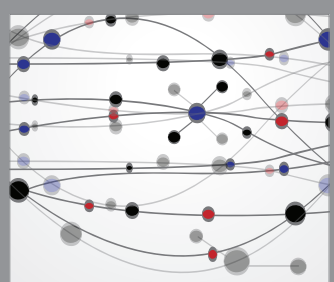

The Scientific World Journal
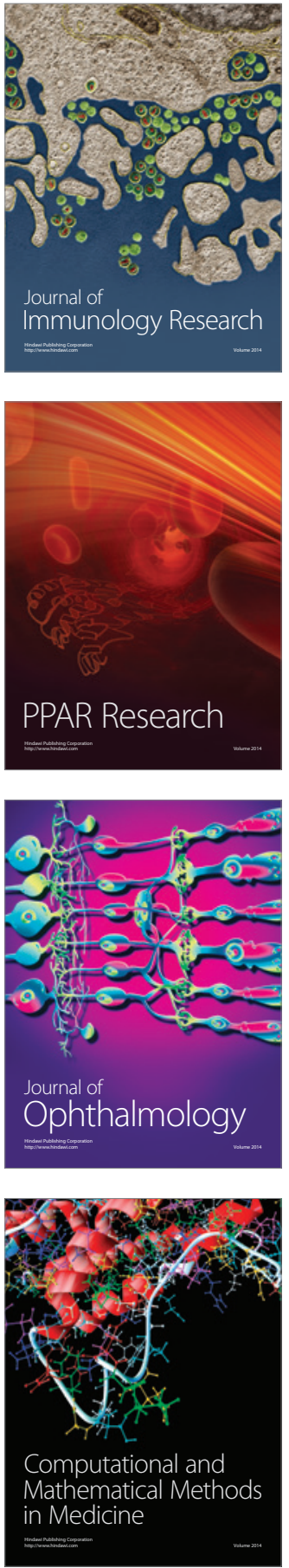

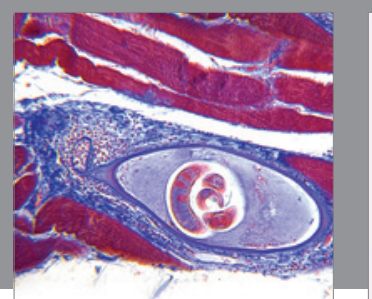

Gastroenterology Research and Practice

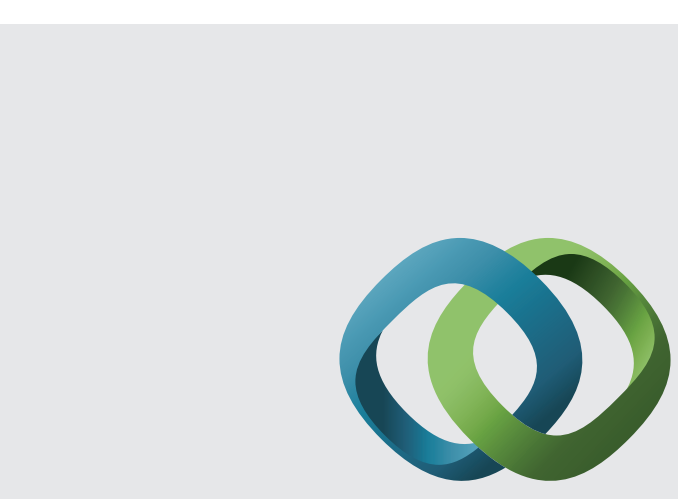

\section{Hindawi}

Submit your manuscripts at

http://www.hindawi.com
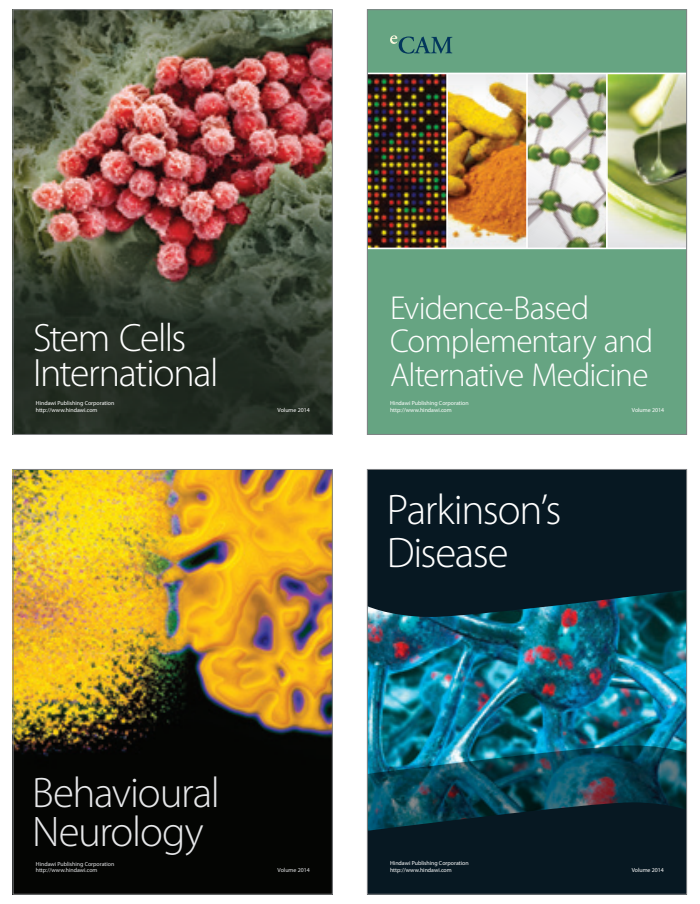
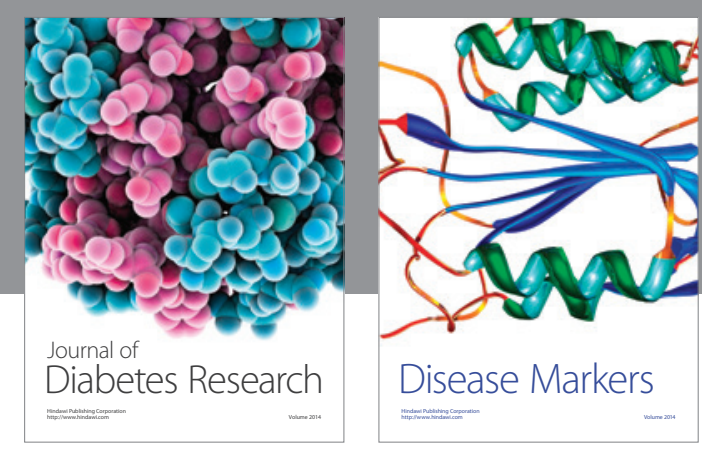

Disease Markers
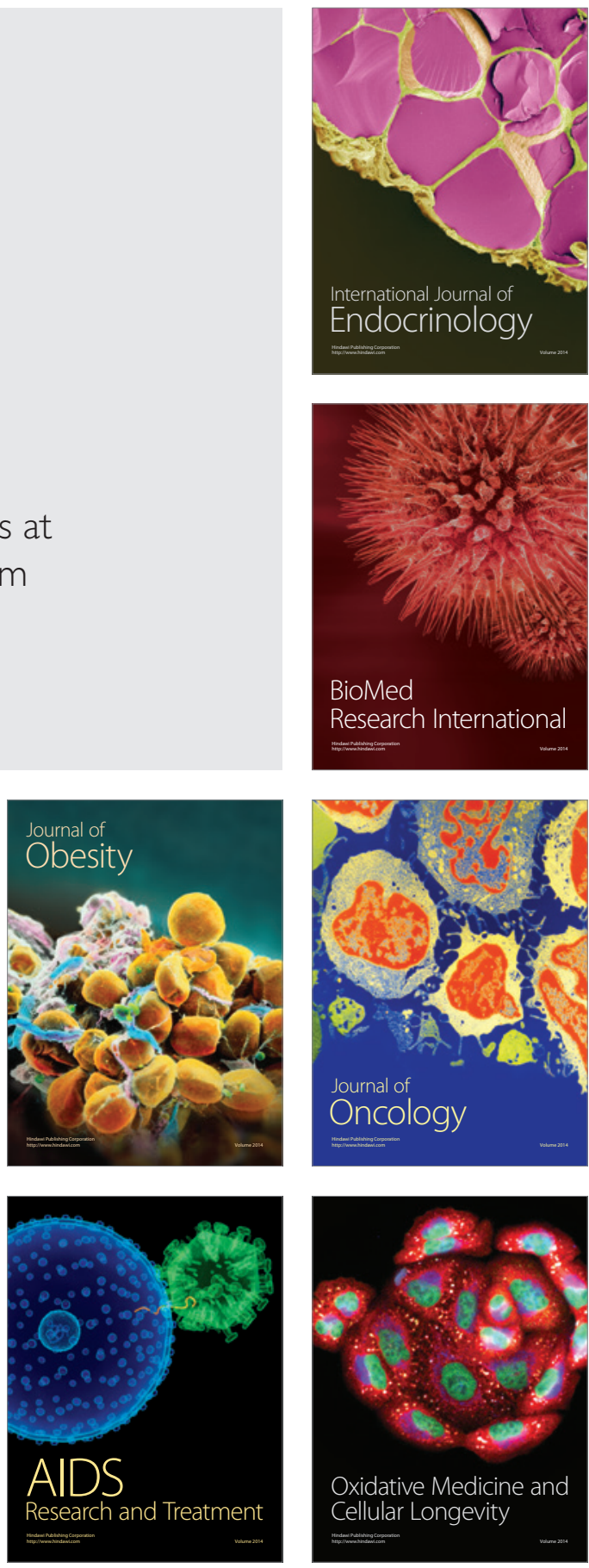